\title{
Guest editorial /Editorial convidado
}

\section{INTERDISCIPLINARITY AND SPEECH-LANGUAGE PATHOLOGY AND AUDIOLOGY}

The growth of Speech-Language Pathology and Audiology as a science is remarkable. The creation of the first four specializations, in 1996, by the Brazilian Council of Speech-Language Pathology and Audiology Audiology, Language, Orofacial Motricity and Voice - represents a milestone of that growth. The emergence of key specialties, such as Dysphagia, Public Health and, later, Educational Speech-Language Therapy, reinforces the hypothesis of how this science evolved by meeting national standards of excellence, with many of these areas becoming international references.

If, on the one hand, we understand that the specialties collaborate to the specific growth of the fields that make up the profession, on the other, we believe that, in the future, all of them will be indissociable, as will be the dialogue with other fields of knowledge, for a better understanding of the complex workings of human communication and its disorders. In this sense, interdisciplinarity appears to be a necessity that is more and more present in the scientific field, reflected in our practices.

The interdisciplinarity is thus understood as "the convergence of two or more fields of knowledge, not belonging to the same class, which contributes to the advancement of the frontiers of science and technology, transferring methods from one field to the other, generating new knowledge or disciplines and contributing to the rise of a new professional with a distinct profile, with a solid and inclusive basic education". It also implies "a new form of knowledge production, because it implies theoretical and methodological exchanges, generating new concepts and methodologies, and increasing degrees of inter-subjectivity, in order to suit the multiple nature of phenomena with greater complexity"(1).

This concept, applied to Speech-Language Pathology and Audiology, makes us think that it was born from that milestone, as it is impossible to think of a scientific, teaching and professional practice that is any different from the concept described.

In this scenario, we bring up the theme of the XXIII Brazilian Congress and XIX International Congress of Speech-Language Pathology and Audiology, promoted by the Brazilian Society of Speech-Language Pathology and Audiology: Interdisciplinarity in Speech-Language Pathology and Audiology. The proposal of this year's edition of the event is to expand the discussion on the state of the art of each specialty from the point of view of interdisciplinarity. The major challenge for the scientific departments and commissions is to deepen the reflections of what is its role within work teams, and to rescue the interrelations of Speech-Language Pathology and Audiology with professions in the fields of health and education.

As is a mark of the two administrations of the current board, each committee and every department received a themed room, which enabled the development of the subject of Interdisciplinary in Speech-Language Pathology and Audiology. The sessions were divided in four different types of activities. The Departmental Symposia are intended for discussions of experts in the field with different approaches around a theme. In the Interdepartmental Symposia, we intend to approach common issues from the perspective of different departments of the Brazilian Society of Speech-Language Pathology and Audiology (SBFa). The Interdisciplinary Symposia are intended to demonstrate the joint work of Speech-Language Pathologists and professionals in related fields. The That's How I Do It sessions were meant as a time to be up-to-date with great references in every field of our profession. For this edition, the scientific departments also prepared some instructional courses, in which attendees have the opportunity to deepen their knowledge on specific issues underlying each field.

One of our rooms was exclusively intended for International Speech-Language Pathology and Audiology, where we will welcome practitioners and researchers from Latin America, North America and Europe. The highlight of this event will be the exchange between Brazilian Speech-Language Pathologists and representatives of these continents. 
The Graduate Room is again being built with the purpose of updating the knowledge regarding the education of masters and doctors of programs accredited by the Coordination for the Improvement of Higher Education Personnel (CAPES). This room will also discuss the updating of information on our leading journals in Speech-Language Pathology and Audiology. Our directors have, therefore, a commitment to allocate space where scientific production in Speech-Language Pathology and Audiology may be discussed, which is very relevant at a time when many Brazilian Speech-Language Pathologists develop their research in interdisciplinary graduate programs. It seems appropriate that, at a conference with this theme, we can be able to discuss contemporary graduate programs, since there is a global trend of increased research and academic program groups dealing with interdisciplinary issues ${ }^{(2)}$.

The Science and Profession Room will feature a master lecture in a special time, organized by the Brazilian Council of Speech-Language Pathology and System of Regional Councils. Likewise, the Speech-Language Pathology and Audiology Unions will have moments for presentation and reflection on the paths of our professional associations. The continued partnership with professional associations that provide vigilance and guidance is also a commitment by the SBFa to its members.

The merit award in Speech-Language Pathology and Audiology, the highlight awards of the departments and commission, the awards of Honorable Mention for Excellence in Speech-Language Pathology and Audiology, best theses and dissertations and prizes for the best campaigns are still a mark of our annual meetings. It's a celebration of Speech-Language Pathology and Audiology as a science and of its researchers, with outstanding works and actions, being recognized by their peers.

We started this editorial highlighting the growth of Speech-Language Pathology and Audiology as a science, especially how much the specialties contributed to this growth. In 2014, new specialties were instituted by the Brazilian Council of Speech-Language Pathology and Audiology (CFFa): Labor-related Speech-Language Pathology and Audiology, Neurofunctional Speech-Language Pathology and Audiology, Gerontology and Neuropsychology. Although this movement is still happening within a disciplinary logic, it increasingly reflects the indissociation of different fields, expressed in the names of each specialty, indicating that we are walking towards collaborative, interdisciplinary practices. Although the specific knowledge is very necessary, and it produces knowledge to prove its response capacity, in our congresses, we will increasingly have to create moments for joint discussion in interdisciplinary sessions. In this scenario, the SBFa shall encourage and support each department in promoting their specific events to discuss the legitimacy that is incumbent upon them.

Undoubtedly, the movement of the profession historically has led us to understand that interdisciplinary Speech-Language Pathology and Audiology is needed nowadays. The SBFa feels therefore fully realized in proposing this theme for the 2015 edition.

Finally, Motivation and Communication will be the master lecture that will close the congress this year. A very relevant theme in the current scenario, with the many ethical challenges and social mobilization needs in our country.

We are excited and happy with the accomplishment of another annual congress. Organizing one of the largest scientific events in Speech-Language Pathology and Audiology is not an easy task, but it is a great opportunity to witness the great advances achieved by this science.

Hilton Justino da Silva e Marileda Tomé Scientific Director of SBFa.

\section{REFERENCES}

1. Capes, 2014, Documento de Área 2013 (Área Interdisciplinar), http://www.capes.gov.br

2. Philippi Junior A, Silva Neto AJ (orgs.). Interdisciplinaridade em Ciência, Tecnologia e Inovação. Barueri: Ed. Manole; 2011. 